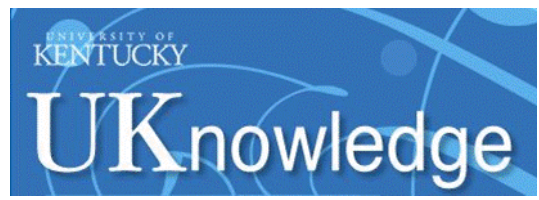

University of Kentucky

UKnowledge

\title{
On the Feasibility of Carbon Nanotube Windings for Electrical Machines - Case Study for a Coreless Axial Flux Motor
}

\author{
Vandana Rallabandi \\ University of Kentucky, vandana.rallabandi@uky.edu \\ Narges Taran \\ University of Kentucky, narges.taran@uky.edu \\ Dan M. Ionel \\ University of Kentucky, dan.ionel@uky.edu \\ John F. Eastham \\ University of Bath, UK
}

Follow this and additional works at: https://uknowledge.uky.edu/peik_facpub

Part of the Power and Energy Commons

Right click to open a feedback form in a new tab to let us know how this document benefits you.

\section{Repository Citation}

Rallabandi, Vandana; Taran, Narges; Ionel, Dan M.; and Eastham, John F., "On the Feasibility of Carbon Nanotube Windings for Electrical Machines - Case Study for a Coreless Axial Flux Motor" (2016). Power and Energy Institute of Kentucky Faculty Publications. 49.

https://uknowledge.uky.edu/peik_facpub/49

This Conference Proceeding is brought to you for free and open access by the Power and Energy Institute of Kentucky at UKnowledge. It has been accepted for inclusion in Power and Energy Institute of Kentucky Faculty Publications by an authorized administrator of UKnowledge. For more information, please contact UKnowledge@lsv.uky.edu. 


\title{
On the Feasibility of Carbon Nanotube Windings for Electrical Machines - Case Study for a Coreless Axial Flux Motor
}

\author{
Digital Object Identifier (DOI) \\ https://doi.org/10.1109/ECCE.2016.7855306
}

\section{Notes/Citation Information}

Published in 2016 IEEE Energy Conversion Congress and Exposition (ECCE).

(C) 2016 IEEE Copyright Notice. "Personal use of this material is permitted. Permission from IEEE must be obtained for all other uses, in any current or future media, including reprinting/republishing this material for advertising or promotional purposes, creating new collective works, for resale or redistribution to servers or lists, or reuse of any copyrighted component of this work in other works."

The document available for download is the authors' manuscript version that is accepted for publication. The final published version is copyrighted by IEEE and available as: V. Rallabandi, N. Taran, D. M. Ionel and J. F. Eastham, "On the feasibility of carbon nanotube windings for electrical machines - Case study for a coreless axial flux motor," 2016 IEEE Energy Conversion Congress and Exposition (ECCE), Milwaukee, WI, 2016, pp. 1-7. doi: 10.1109/ECCE.2016.7855306

This conference proceeding is available at UKnowledge: https://uknowledge.uky.edu/peik_facpub/49 


\section{On the Feasibility of Carbon Nanotube Windings for Electrical Machines - Case Study for a Coreless Axial Flux Motor}

\author{
Vandana Rallabandi, Narges Taran, Dan M. Ionel \\ Department of Electrical and Computer Engineering, \\ University of Kentucky, \\ Lexington, Kentucky, USA \\ Email: vandana.rallabandi@uky.edu
}

\author{
John F. Eastham \\ University of Bath, \\ Claverton Down, \\ Bath, UK \\ Email: jfeastham@aol.com
}

\begin{abstract}
The latest developments in carbon nanotube (CNT) wires and yarns attract great interest for potential application to electromagnetic devices, such as electrical machines and transformers. The CNT material properties are largely different from copper and aluminum in terms of electrical conductivity, mass density, and thermal transfer, creating a new design paradigm for which the traditional rules and device topologies no longer apply. This paper proposes a brushless permanent magnet multidisc axial flux construction with coreless stator and special windings and minimal rotor back iron, as a suitable topology for CNT winding application. Specific analytical closed-form sizing equations, as a function of winding electric conductivity, machine dimensions, and operating speed/frequency, are derived and employed in a systematic comparative study over a range of $\mathrm{kW}$ power ratings and speeds between 1,000 and $10,000 \mathrm{rpm}$. The numerical study is complemented by $3 \mathrm{D}$ and $2 \mathrm{D}$ electromagnetic FEA. The results show that the designs with CNT windings may have substantially higher specific power per mass, particularly at high rotational speeds and/or supply frequency, where the combined effect of DC and AC conduction losses in the windings is significant.
\end{abstract}

Index Terms - axial flux machine, coreless motor, sizing equations, carbon nanotube conductors, CNT wire, CNT yarn.

\section{INTRODUCTION}

Carbon nanotubes (CNT) are tubular cylinders of a planar hexagonal lattice of carbon atoms, exhibiting excellent electrical (electrical conductivity of $100 \mathrm{MS} / \mathrm{m}$ ), thermal (3500 $\mathrm{W} / \mathrm{mK}$ thermal conductivity), and mechanical properties, along with low mass density $(1500 \mathrm{~kg} / \mathrm{m} 3)$. There are three basic types of CNT structures: armchair (metallic), zig-zag, and chiral (with semiconductor properties). Carbon nanotubes may be single walled (SWCNT-i.e. with only one tubular cylinder), double walled (DWCNT-two concentric tubular cylinders, with the same or different basic structures), and multi-walled (MWCNT-multiple concentric tubular cylinders, of the same or different basic structure) [1].

Carbon nanotubes are synthesized by laser ablation, arc discharge or chemical vapor deposition and have diameters of the order of micrometers. CNT fibers (or yarns) are assemblies of axially aligned nanotubes. They are synthesized by wet or dry spinning, or are formed during CNT synthesis (direct synthesis). They have very good mechanical properties and low density. For electrical wiring, CNT fibers are joined in parallel and insulated. These wires tend to be more resistive than copper wires. However, they have a low temperature coefficient of resistance, and exhibit low skin effect. One of the first developments of CNT fibers coated with standard insulation material is discussed in [2].

Carbon nanotubes have anisotropic electrical conductivity, the highest conductivity is along the axial direction, and it is much lower across the tube. In order to achieve high conductivity in a CNT yarn, all the individual nanotubes must be axially aligned. The conductivity achieved depends upon the extent to which all the nanotubes constituting a yarn are aligned. The fibers produced today have a wide range of conductivities due to limited control over the alignment. Another reason for the reduced conductivity is that the spinning methods produce nanotubes of different structures, (not all metallic) [1].

The use of carbon-nano tube technology is previously attempted in electrical machines. Using CNT wires in a high frequency transformer is discussed in [3]. It was shown that a transformer with CNT windings performs as expected over a wide frequency range, but exhibits higher resistance than its counterpart with copper windings. The use of CNT wires was also successfully demonstrated in a $30 \mathrm{~W}, 15,000 \mathrm{rpm}$ permanent magnet synchronous machine with concentrated coils in [4]. The developed machine had an efficiency of approximately $69 \%$.

This paper studies the replacement of conventional copper coils with CNT coils in a multi-disc Axial Flux Permanent Magnet (AFPM) motor. This motor is inspired by a machine originally proposed for stratospheric unmanned aircraft propulsion [5], [6], [7]. The next section is devoted to reviewing the development of CNT wires and their usage in electrical machine winding. Section III discusses the structure of the machine and sizing equations. The Finite Element Analysis (FEA) model of the machine with copper coils is studied in section IV. In the next section, the effect of replacing copper coils with CNT material coils is explored. Since having 


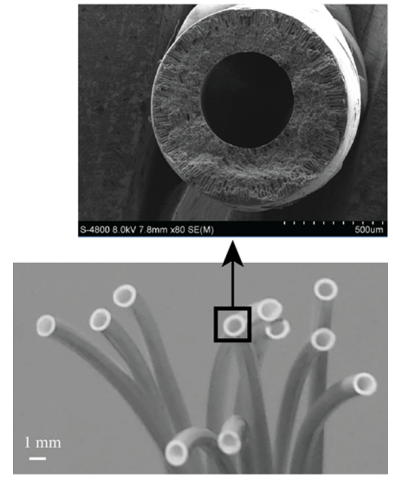

(a)

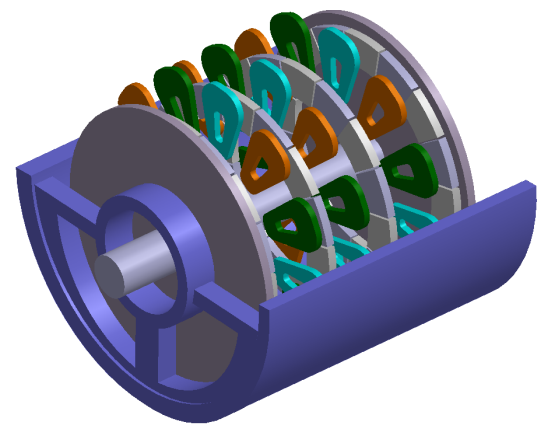

(b)

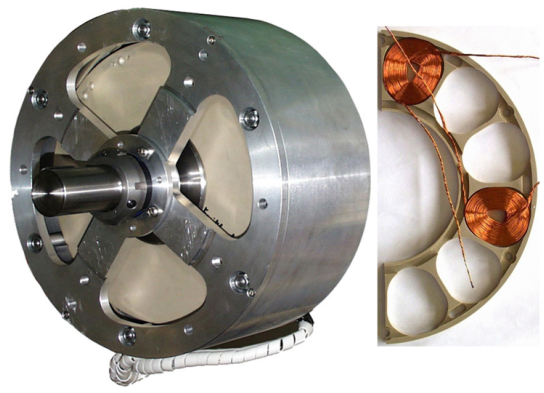

(c)

Figure 1. Recently developed carbon nanotube (CNT) wires and yarns are employed for a PM brushless multi-disc coreless axial flux (AFPM) motor, which was previously demonstrated for the propulsion of a small stratospheric aircraft. Only the end modules include rotor back iron. The PMs are attached to a composite structure (omitted from the figure) which is connected to the shaft. Illustrated in the figure: (a) CNT wires, (b) the assembly of the model (supporting discs for the coils are not shown), (c) prototype AFPM brushless multi-disc coreless motor.

virtually no skin effect in CNT wires makes them especially interesting candidates in high speed applications, section VI is dedicated to comparing CNT wired machines specifications in higher speed applications-up to $10,000 \mathrm{rpm}$. The last part concludes the significant points of the present study.

\section{Technology ReVIEW}

In view of the promising properties of CNTs and the attempts being made to continuously improve them, much of the recent work discusses the use of carbon nanotube windings in wiring and electrical machines. The use of CNT material in aerospace wiring was discussed in 2010 [8]. The CNT wires therein were doped with an ionic $\mathrm{KAuBr} 4$ solution, and had electrical conductivity of $1.3 \mathrm{MS} / \mathrm{m}$ and improved mechanical strength, with lower density. One very recent breakthrough in Japan has achieved a real landmark in electrical conductors. Using an aligned CNT-Cu composite comprised of 45 vol.\% $\mathrm{CNT}$ in electroplated $\mathrm{Cu}$, which interpenetrated and plated interstitial space between the CNTs, a stable ampacity of $6 \times 10^{8} \mathrm{~A} / \mathrm{cm} 2$ (100 times greater than $\mathrm{Cu}$ ), with a conductivity nearly the same as $\mathrm{Cu}\left(2.3-4.7 \times 10^{5} \mathrm{~S} / \mathrm{cm}\right.$, compared to $\mathrm{Cu} 5.8 \times 10^{5} \mathrm{~S} / \mathrm{cm}$ ) was clearly demonstrated [9]. Ampacity is defined as the maximum current density at which resistivity remains constant. Copper composite CNT wire has attracted interest owing to this development, and attempts are being made to develop an ultraconductive copper- carbon nanotube wire (Ultrawire) [10]. Carbon nanotube wires have been employed for a high frequency transformer [3] and a permanent magnet synchronous machine [4].

In the present paper, an AFPM coreless machine topology is selected for a feasibility and comparative study between copper and CNT windings. The stator construction is coreless and comprises only the conductive coils and a light supporting disc structure. The machine was originated from a study for stratospheric unmanned aircraft propulsion [5], [6], [7]. Multiple stator and rotor discs were employed to obtain high power density.

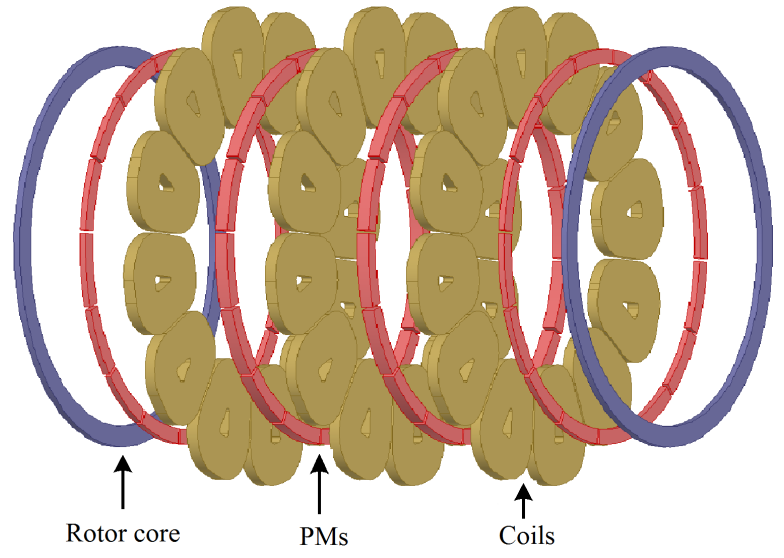

Figure 2. Components of the proposed coreless AFPM machine. Supporting discs for the stator coils and rotor PMs are not shown for clarity.

In such a machine, the mass of stator coils made of copper wire represents a significant proportion of the total mass of the machine. The conductors, which are directly placed in a substantially large air-gap, are exposed directly to the main air-gap flux, and therefore significant eddy current and supplementary AC losses occur in the windings. These considerations indicate that replacing copper coils with CNT coils in multi-disc coreless AFPM machines of the type previously developed could be advantageous. The idea is represented in Fig. 1, which shows the prototype axial flux machine of [7].

\section{MAChine STRUCTURE AND SIZING EQUATIONS}

The exploded view of the 3D model is shown in Fig. 2. PMs are surface mounted and stator stacks are coreless. Each rotor stack includes 16 poles and each stator stack contains 12 coils.

From first principles, power output of a coreless axial flux machine can be derived as:

$$
P_{e m}=\frac{B_{m} A \pi^{2} n D_{o}^{3}(1+\lambda)\left(1-\lambda^{2}\right)}{240 \sqrt{2}},
$$




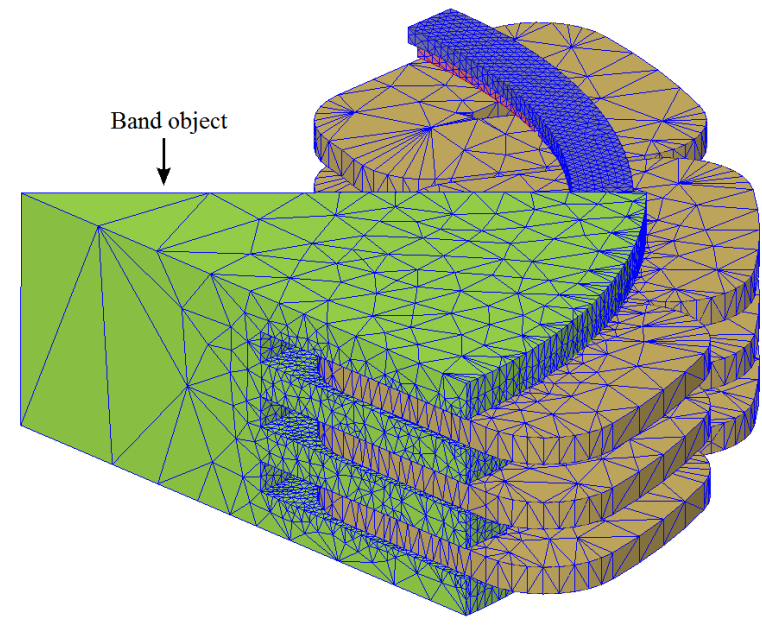

Figure 3. One quarter of the model meshed with finite tetrahedral elements. The smaller meshing was utilized for curves as well as surfaces facing the PMs. The band object (the rotating part of the machine including rotors and PMs) is split to provide a better view of the meshing plot for all components.

with:

$$
A=\frac{2 N m I_{r m s}}{\pi D_{m}} ; \lambda=\frac{D_{i}}{D_{o}},
$$

where $B_{m}$ is the maximum value of air-gap flux density; A the current loading; $D_{o}$ the outer diameter; $D_{i}$ the inner diameter; $D_{m}$ the mean diameter; $\mathrm{N}$ the turns per phase; $\mathrm{m}$ the number of phases; $\mathrm{n}$ the electrical speed in rpm; and $I_{r m s}$ the RMS current.

As the work focuses on the replacement of copper conductors with CNT wires, and one of the differences between CNT wires and copper conductors is the value of electrical conductivity, a relation between power and electrical conductivity of the winding of the motor is derived, by keeping the loss per unit conductor volume the same. Thus,

$$
\frac{\left(I^{2} \ell_{m t} N m\right) /(a \sigma)}{a \ell_{m t} N m}=\frac{I^{2}}{a^{2} \sigma}=K^{2},
$$

where $K$ is a constant, $\ell_{m t}$ the length of mean turn, $\sigma$ the conductivity, and $a$ is the conductor cross sectional area.

$$
a \approx L \frac{\pi D_{i}}{2 N_{c}}=L \frac{\lambda \pi D_{o}}{2 N_{c}},
$$

Equation (4) represents that the conductor cross sectional ares, $a$, is proportional to the product of the axial length of the coil, $L$, and the diameter of the machine. This gives,

$$
I=K \sqrt{D_{o}^{2} L^{2} \sigma},
$$

Substituting this in the power equation gives,

$$
P_{e m}=\frac{B_{m} K L \sqrt{\sigma} 2 N \pi n D_{o}^{3}\left(1-\lambda^{2}\right)}{120 \sqrt{2}} ; P_{e m} \propto D_{o}^{3} \sqrt{\sigma} L
$$

Thus, keeping all geometric parameters equal, at a given speed, the power output from the machine is proportional to the square root of its conductivity. Carbon nanotube wires have much lower conductivity than copper. Therefore, in order to compensate for the reduction in power output due to the
Table I

SPECIFICATIONS OF THE EXPERIMENTAL CORELESS AFPM MACHINE USED IN THE STUDY

\begin{tabular}{lr}
\hline Rated power & $2.2 \mathrm{~kW}$ \\
Rated speed & $1000 \mathrm{rpm}$ \\
Active outer diameter & $290 \mathrm{~mm}$ \\
Total axial length & $59 \mathrm{~mm}$ \\
Total active mass & $9.52 \mathrm{~kg}$ \\
Rated current & $10 \mathrm{~A}$ \\
EMF constant & $1.7 \mathrm{~V} . \mathrm{s} / \mathrm{rad}$ \\
\hline
\end{tabular}

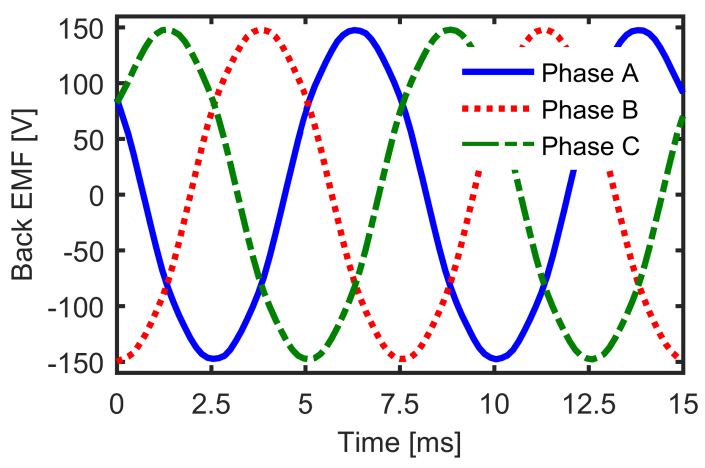

Figure 4. Calculated three-phase back EMF for the motor with copper coilsthe sinusoidal nature is expected for this type of machine.

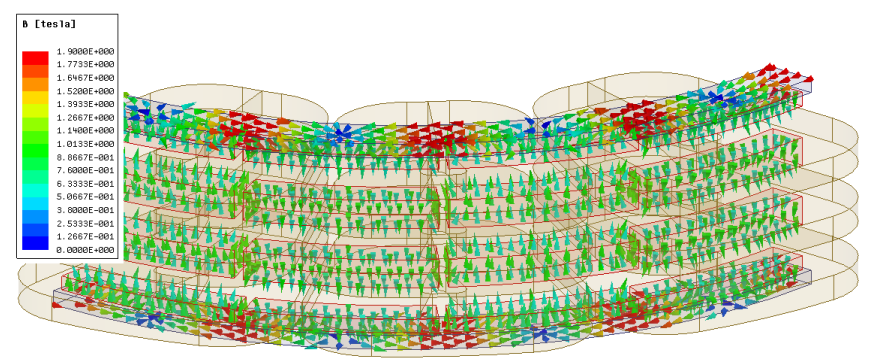

Figure 5. Magnetic flux density and flux path 3D representation in the motor with copper coils.

reduction in conductivity, the dimensions (axial length or diameter) of the CNT based machine, or the number of stator discs must be increased.

\section{Finite ELEMENT BASED MOdel of AFPM With COPPER COILS}

Detailed finite element analysis (FEA) is performed on the coreless AFPM machine of [5], [6]. This motor consists of four rotor disks and three coreless stator disks. The specifications of the motor are provided in Table I. ANSYS Maxwell 3D is used for the simulations [11]. Time transient FEA with motion is used. Taking advantage of symmetry only one quarter of the model ( 2 pole pairs) was analyzed. Fig. 3 represents the meshing plot for $1 / 4^{\text {th }}$ section of the geometry. Finer meshing for curves and surfaces facing PMs was employed while larger 


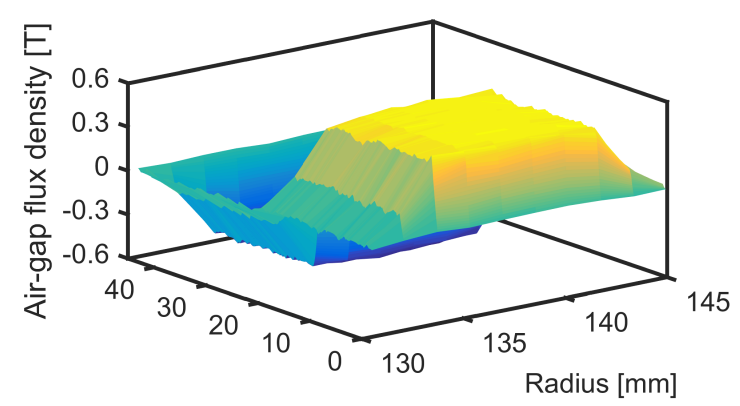

Angular position [mech deg]

(a)

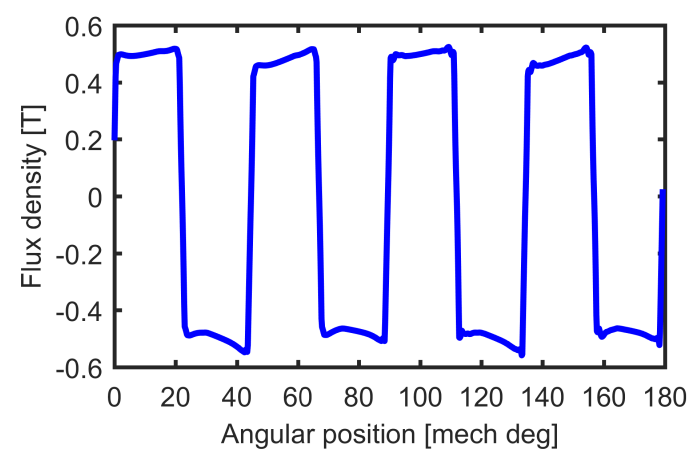

(b)

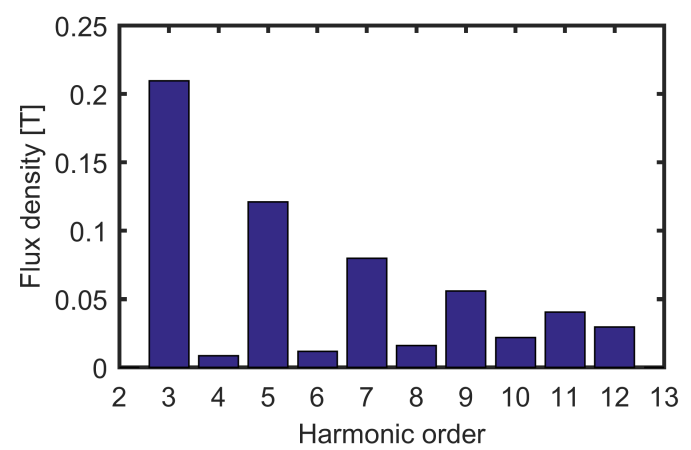

(c)

Figure 6. (a) Open circuit air-gap flux density at different radii and angular positions. (b) Open circuit air-gap flux density at the mean radius. (c) Harmonic spectrum of the open circuit air-gap flux density from which the fundamental harmonic, that has an amplitude of $0.6 \mathrm{~T}$, has been omitted. The rich harmonic content produces supplementary losses in the airgap windings.

mesh was utilized for the other parts in order to achieve the appropriate number of meshes and reliable results.

Open circuit transient analysis for a rotation of two pole pairs confirms the sinusoidal waveform for back EMF. The simulation results for back EMF is represented in Fig. 4. Magnetic flux density for the machine is illustrated in Fig. 5 . The vectors clearly show the axial direction of magnetic flux in the air-gap and the flux path in the magnetic circuit including rotor back iron, PMs, air-gap, and windings.

The variation of the axial component of air-gap flux density due to the PMs with the position along the circumferential

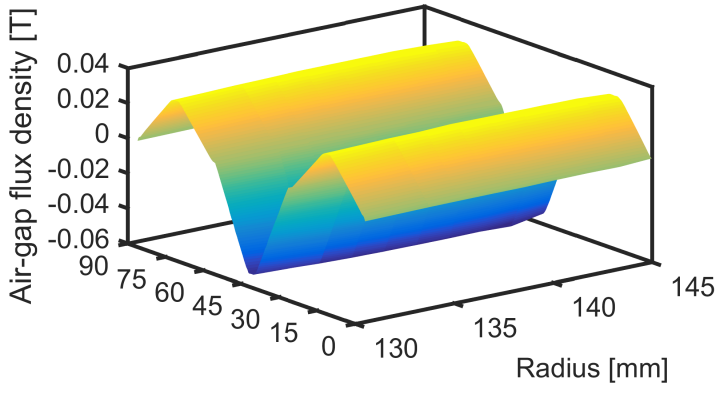

Angular position [mech deg]

(a)

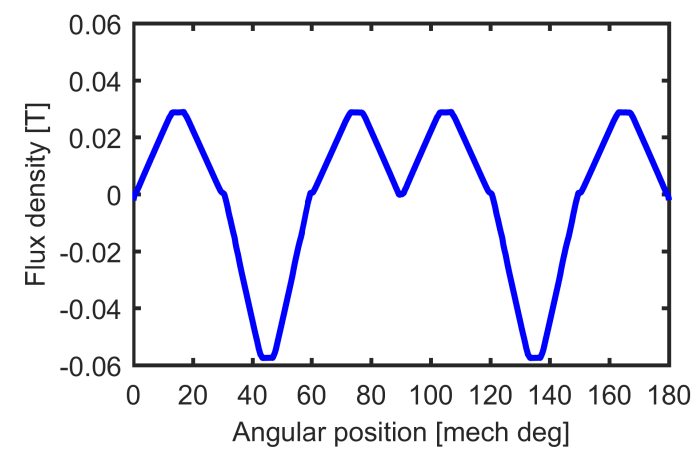

(b)

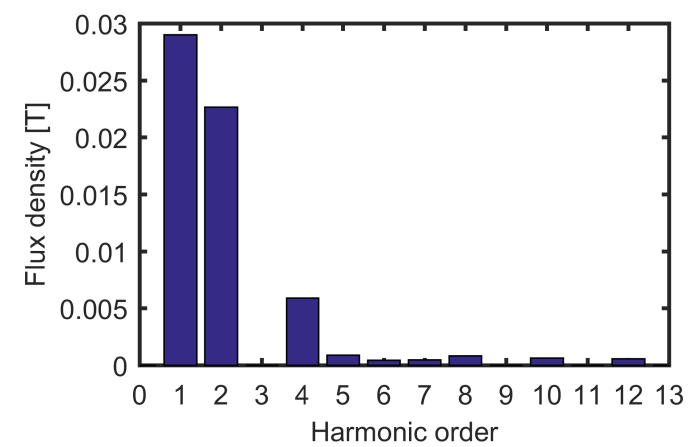

(c)

Figure 7. (a) Air-gap flux density due to armature reaction at different radii and angular positions. (b) Air-gap flux density due to armature reaction at the mean radius. (c) Harmonic spectrum of the air-gap flux density due to armature reaction. Second harmonic interacts with the magnets to produce torque. The fundamental introduces loss in the rotor back iron and PMs, which could become significant at high speeds.

direction is shown in Fig. 6, along with its harmonic spectrum. It is seen from this figure that the flux density has in addition to its 16 pole (fundamental) component, $3^{\text {rd }}, 5^{\text {th }}$ harmonic components. All these components would cause loss in the conductors.

Load analysis was performed by applying three-phase sinusoidal current excitation to the winding terminals. The obtained torque is presented in Fig. 8. The variation of the axial component of air-gap flux density due to the coils alone with the angular position is seen in Fig. 7, with its harmonic 


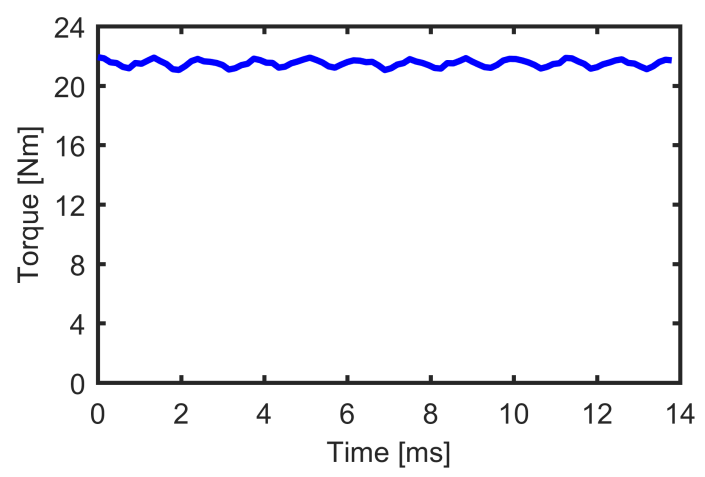

Figure 8. Instantaneous torque for the machine type in the study with copper coils. The almost ripple free nature is in line with expectations for the machine under study.

spectrum. It can be seen that the fundamental component of this field is the 8 pole component ( 2 cycles over 180 degrees mechanical as seen in Fig. 7b). Thus, the $2^{\text {nd }}$ harmonic component of this field interacts with the magnets to produce torque. The fundamental ( 8 pole component) would simply produce losses in the laminated rotor back, and the PMs, which could become important at high speeds.

\section{EFFECT OF REPLACING COPPER WINDINGS WITH CNT WINDINGS}

Three different parametric studies are carried out in order to quantify the benefits of replacing copper coils with CNT coils. The material properties used in these parametric studies are given in Table II. As the properties of CNT yarns reported in literature vary over a range, the calculations are performed for two values of conductivity i.e. $2.4 \mathrm{MS} / \mathrm{m}$ (CNT\# 1) and $10 \mathrm{MS} / \mathrm{m}$ (CNT\# 2). Conductivity of $10 \mathrm{MS} / \mathrm{m}$ has been reported for CNT yarns by the company Teijin Aramid [4]. The density and conductivity values are from [4]. The temperature coefficient of resistance for CNT fibers is reported to be between 0.001 to $0.002 / \mathrm{K}$ [1]. Hence, it is taken to be 0.0015 $/ \mathrm{K}$ in this study. Also, the same slot fill factor is used for copper and CNT coils.

The lower conductivity in CNT coils can be offset in three different ways. These form the subjects of the three parametric studies reported here. In the first parametric study, the required torque is obtained by stacking multiple stator rotor units together. The second study considers situations where more space is made available for the larger coils by increasing their axial length. Since in this case the effective air-gap is higher, the PM thickness is also increased in order to compensate for the additional reluctance in the magnetic circuit, as shown in Fig. 9

In the third parametric study the diameter of the machine with CNT coppers is increased in order to accommodate larger coil width and hence compensate for the lower conductivity. In all the cases, the loss per unit dissipation area and developed torque are maintained the same as in the copper based ma-
Table II

Material Properties With Best and Worst Case Conductivities FOR CNT WIRES.

\begin{tabular}{lccc}
\hline Material & $\begin{array}{c}\text { Conductivity } \\
{[\mathrm{MS} / \mathrm{m}]}\end{array}$ & $\begin{array}{c}\text { Density } \\
{\left[\mathrm{kg} / \mathrm{m}^{3}\right]}\end{array}$ & $\begin{array}{c}\text { Temperature coefficient } \\
\text { of resistance }[/ \mathrm{K}]\end{array}$ \\
\hline Copper & 58.0 & 8960 & 0.0038 \\
Aluminum & 35.0 & 2700 & 0.0043 \\
CNT \#1 & 2.4 & 1500 & 0.0015 \\
CNT \#2 & 10.0 & 1500 & 0.0015 \\
\hline
\end{tabular}

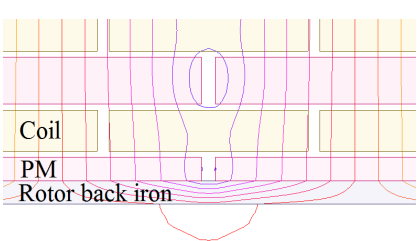

(a)

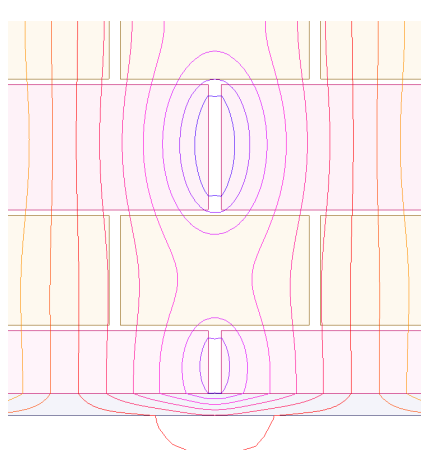

(b)
Figure 9. Flux lines in a section of the multi-disc AFPM machine in this study. Illustrated in the figure: (a) Copper based machine, (b) CNT based machine with increased axial length. The thickness of the PMs is increased to compensate for the higher reluctance of the magnetic circuit due to the larger coils.

chine. The results of the comparative study at the rated speed of $1000 \mathrm{rpm}$ is shown in Table III.

It is worth mentioning that the overall winding loss would be higher, at least at the speed of $1000 \mathrm{rpm}$ in case of the machine with CNT coils. The higher overall loss could be reduced by improving the slot filling factor as discussed in [12]. Table III shows that torque to active weight of the machine with CNT coils can be improved to around $3 \mathrm{Nm} / \mathrm{kg}$. A continuous torque rating of $30 \mathrm{Nm}$, with active weight of $6.8 \mathrm{~kg}$, (i.e. torque to weight ratio of of $4.4 \mathrm{Nm} / \mathrm{kg}$ ) was reported for a 16 pole AFPM designed for direct drive applications [13]. The machine therein employed a single stator, with toroidally wound coils, which could account for the discrepancies in the torque to weight ratios of the machines and could be investigated in future work.

\section{PERFORMANCE COMPARISONS FOR HIGHER SPEED MACHINE DESIGNS}

It can be seen from Table III that at the speed of $1000 \mathrm{rpm}$, in order to produce the same torque, the machine designed with CNT \# 1 (worst case) needs to have slightly more active mass than the machine with copper coil. However, the machine with CNT \#2 (best case) has about $\frac{2}{3}^{\text {rd }}$ the mass. Another point to be noted from this table is that though the active masses of the CNT based machines, in all parametric studies, are less 
Table III

MOTOR DESIGNS FOR $2.2 \mathrm{KW}, 1000$ RPM RATING. THE PARAMETRIC STUDY 1 HAS HIGHER NUMBER OF STACKS COMPARED TO COPPER BASED MACHINE, THE PARAMETRIC STUDY 2 HAS LONGER STATOR AXIAL LENGTH, AND THE PARAMETRIC STUDY 3 HAS INCREASED DIAMETER.

\begin{tabular}{lrrrrrrr}
\hline & & \multicolumn{2}{c}{ Parametric 1 } & \multicolumn{2}{c}{ Parametric 2 } & \multicolumn{2}{c}{ Parametric 3 } \\
& Copper & CNT \#1 & CNT\#2 & CNT\#1 & CNT\#2 & CNT\#1 & CNT\#2 \\
\hline Active axial length [mm] & 59 & 178 & 110 & 199.4 & 103.5 & 59 & 59 \\
Active outer diameter [mm] & 290 & 290 & 290 & 290 & 290 & 481.4 & 371.2 \\
Number of turns & 80 & 28 & 58 & 81 & 79 & 71 & 66 \\
PM mass [kg] & 1.54 & 5.14 & 3.08 & 6.35 & 3.07 & 4.89 & 2.74 \\
Steel mass [kg] & 0.79 & 0.79 & 0.79 & 0.79 & 0.79 & 2.18 & 1.29 \\
Coil mass [kg] & 7.20 & 4.02 & 2.41 & 4.97 & 2.40 & 3.32 & 1.98 \\
Total active mass $[\mathrm{kg}]$ & 9.54 & 9.95 & 6.28 & 12.12 & 6.26 & 10.40 & 6.01 \\
Total volume $\left[\mathrm{m}^{3}\right]$ & 0.0057 & 0.0171 & 0.0106 & 0.0192 & 0.0100 & 0.0157 & 0.0093 \\
Specific torque $[\mathrm{Nm} / \mathrm{kg}]$ & 2.09 & 2.01 & 3.18 & 1.65 & 3.19 & 1.92 & 3.33 \\
Specific torque $\left[\mathrm{Nm} / \mathrm{m}^{3}\right]$ & 3508.77 & 1169.59 & 1886.79 & 1041.67 & 2000.00 & 1273.88 & 2150.54 \\
\hline
\end{tabular}

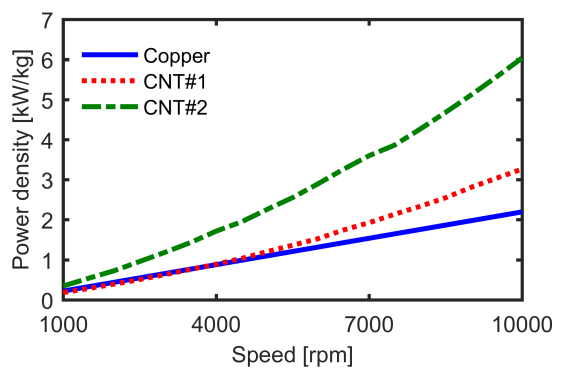

(a)

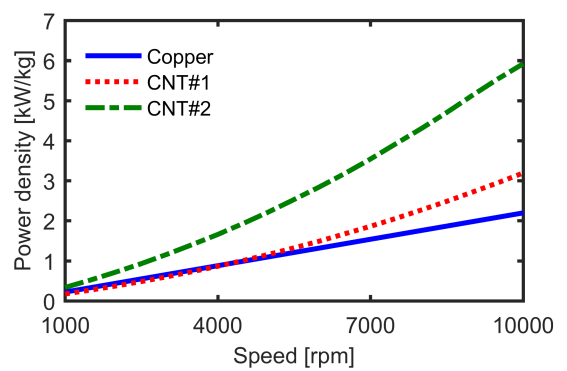

(b)

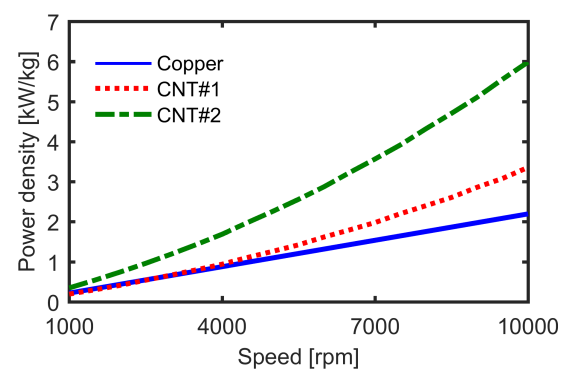

(c)

Figure 10. Variation of power density with speed. Illustrated in the figure: (a) parametric study 1- number of stator stacks in the CNT based machine is increased, (b) parametric study 2- axial length of the stator for the CNT based machine is increased, (c) parametric study 3- outer motor diameter for the CNT based machine is increased.

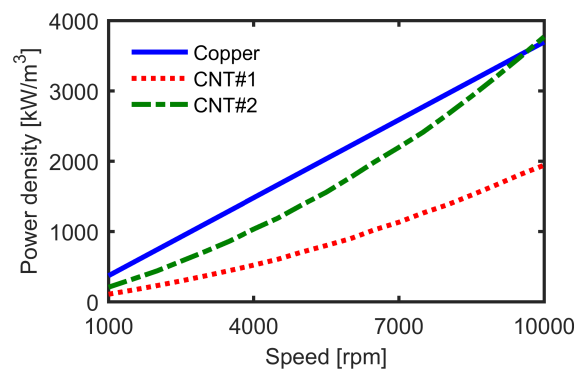

(a)

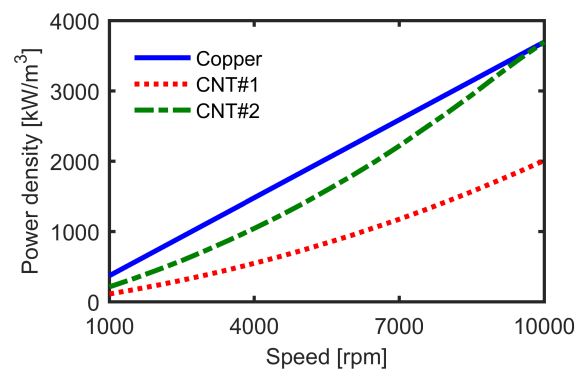

(b)

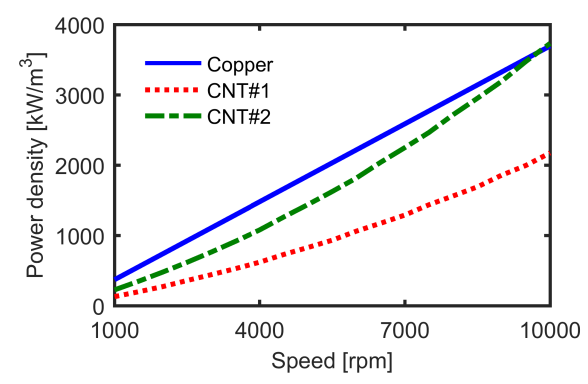

(c)

Figure 11. Variation of power per unit of volume with speed. Illustrated in the figure: (a) parametric study 1- number of stator stacks in the CNT based machine is increased, (b) parametric study 2- axial length of the stator for the CNT based machine is increased, (c) parametric study 3- outer motor diameter for the CNT based machine is increased.

than that of the copper based machine, the space occupied by the former is higher.

At higher speeds, and therefore higher operating frequencies, the situation changes due to induced eddy currents in the conductors identified with skin and proximity effects. This effect is quite substantial. For example, in one particular case, for distributed windings, the ratio of $\mathrm{AC}$ to $\mathrm{DC}$ resistance varies from 1 to 4.4 , from DC to $700 \mathrm{~Hz}$. The variation for concentrated windings is higher, from 1 to 9.4 over the same frequency range [14]. In the coreless AFPM machine, this effect is expected to be exacerbated, as the coils are placed in the air-gap and link the fundamental air-gap flux as opposed to conventional machines with stator coils placed in slots, which only see the slot leakage flux.

Taking into account ac winding losses accurately requires either modeling of individual strands or experimental mea- 
surements. Since the exact position and arrangement of the strands needs to be specified, this task becomes particularly challenging when number of turns is large. The experimental measurements reported in [14] for distributed windings are utilized for the purposes of this paper, as the proportion of end coils to the coil length are approximately the same as that of the distributed winding.

Carbon nanotube windings are reported to have virtually no skin effect [1], [4]. This special property makes them interesting candidates for use in high speed coreless axial flux PM machines. The machine, designed for high speed might need special measures to limit the loss in the laminated back iron and the PMs such as thin low loss steel and sub-divided magnets.

The comparison of power density $(\mathrm{kW} / \mathrm{kg})$ of machines designed for different speeds is shown in Fig. 10. This figure reports the results of three parametric studies in which the lower conductivity of CNT is compensated for by increase in a) Number of stator stacks, b) Axial length of the coil and c) Outer diameter of the machine. All the machines are designed for the same torque and have the same loss per unit area. For machine designs at lower speed, the skin effect in copper being low, the increase in dimensions required to accommodate the CNT windings to meet the torque and loss dissipation of the machine with copper windings, is high. At higher speeds, the skin effect in copper is not negligible, and the gap between conductor loss in the CNT and copper reduces. This allows one to design the machine having CNT coils with dimensions not much higher than the machine with copper coils, while meeting the conditions of loss per unit area and torque. This explains the nature of the graphs of Fig. 10 and Fig. 11.

Thus, irrespective of which of the dimensional parameters is increased for the machine CNT coils, at high speeds $(>5000$ $\mathrm{rpm})$, it can be concluded these machines have a significant edge over their counterparts with copper coils.

From Fig. 11, it is seen that for the most part, the machines with CNT coils occupy more space than their copper counterparts. However, at speeds close to $10,000 \mathrm{rpm}$, a CNT based machine may be designed with lower active mass (less than half) than a machine with copper windings, and comparable active volume.

\section{CONCLUSION}

The feasibility of employing carbon nanotube (CNT) windings for electric machines was systematically studied. In order to benefit of the advantages of CNT in terms of low mass density, negligible skin effect, and low coefficient for the resistance increase with temperature, a multi-disc axial flux coreless topology was proposed for brushless PM machines. In such a machine, realized with copper wire, the stator windings account for a significant proportion of the total mass. Furthermore, the ratio of AC to DC losses is high. Therefore, replacing copper coils with CNT coils is particularly beneficial.
A set of sizing equations has been derived, and 3D finite element analysis was used to quantify the performance improvement obtained when the copper coils in such a coreless multi-disc axial flux motor are replaced with CNT windings. The results indicate that a machine with CNT windings may have, in comparison with its copper winding counterpart, higher power density and comparable active volume for high speed and/or frequency ratings.

\section{ACKNOWLEDGMENT}

Special thanks are due to Dr. Matthew Weisenberger and his carbon materials research group at UK-CAER for their contributions on new materials, to Mr. Mark Solveson of ANSYS, Inc. for expert advice on advanced simulation software and to Mr. James R. Hendershot of MotorSolver, LLC for expert advice on practical design and construction of electric motors. The support of University of Kentucky, the L. Stanley Pigman endowment, and ANSYS, Inc. is gratefully acknowledged.

\section{REFERENCES}

[1] A. Lekawa-Raus, J. Patmore, L. Kurzepa, J. Bulmer, and K. Koziol, "Electrical properties of carbon nanotube based fibers and their future use in electrical wiring," Advanced Functional Materials, vol. 24, no. 24, pp. 3661-3682, 2014.

[2] A. Lekawa-Raus, L. Kurzepa, X. Peng, and K. Koziol, "Towards the development of carbon nanotube based wires," Carbon, vol. 68, pp. 597-609, 2014

[3] L. Kurzepa, A. Lekawa-Raus, J. Patmore, and K. Koziol, "Replacing copper wires with carbon nanotube wires in electrical transformers," Advanced Functional Materials, vol. 24, pp. 619-624, 2014.

[4] P. Juha, M. Juho, L. Pia, V. Julia, and O. Marcin, "At the cusp of the next electric motor revolution: Replacing copper with carbon nanomaterials," in International Conference on Energy Efficiency in Motor Driven Systems, 2015.

[5] R. Hill-Cottingham, P. Coles, J. Eastham, F. Profumo, A. Tenconi, and G. Gianolio, "Multi-disc axial flux stratospheric aircraft propeller drive," IEEE Industry Applications Conference, vol. 3, pp. 1634-1639, 2001.

[6] R. Hill-Cottingham, P. Coles, J. Eastham, F. Profumo, A. Tenconi, G. Gianolio, and M. Cerchio, "Plastic structure multi-disc axial flux pm motor," IEEE Industry Applications Conference, vol. 2, pp. 1274-1280, 2002.

[7] F. Profumo, A. Tenconi, M. Cerchio, J. F. Eastham, and P. C. Coles, "Axial flux plastic multi-disc brushless pm motors: performance assessment," Applied Power Electronics Conference and Exposition, vol. 2, pp. 1117-1123, 2004.

[8] J. Alvarenga, "Carbon nanotube materials for aerospace wiring," M.S Thesis, Rochester Institute of Technology, 2010.

[9] C. Subramaniam, T. Yamada, K. Kobashi, A. Sekiguchi, D. N. Futaba, M. Yumura, and K. Hata, "One hundred fold increase in current carrying capacity in a carbon nanotube-copper composite," Nature communications, vol. 4, 2013.

[10] "Ultrawire.eu, ultra conductive copper-carbon nanotube wire, 2014," Available: http://ultrawire.eu/, accessed: 2016-07-06.

[11] ANSYS Maxwell, version 16.2, 2015.

[12] J. Widmer, C. Spargo, G. Atkinson, and B. Mecrow, "Solar plane propulsion motors with precompressed aluminum stator windings," IEEE Transactions on Energy Conversion, vol. 29, no. 3, pp. 681-688, 2014.

[13] F. Caricchi, F. Crescimbini, E. Fedeli, and G. Noioa, "Design and construction of a wheel-directly-coupled axial-flux pm motor prototype for evs," IEEE Industry Applications Society Annual Meeting, vol. 1, pp. 254-261, 1994.

[14] R. Wrobel, D. Salt, A. Griffo, N. Simpson, and P. Mellor, "Derivation and scaling of ac copper loss in thermal modeling of electrical machines," IEEE Transactions on Industrial Electronics, vol. 61, no. 8, pp. 4412-4420, 2014 